\title{
Plasma Concentrations of 18-Hydroxy-11-Deoxycorticosterone and 18-Hydroxycorticosterone Simultaneously Measured in Normal Subjects and Adrenocortical Disorders
}

\author{
Motoko Ojima and Akira Kambegawa* \\ Department of Pathology, Tohoku University School of Medicine, \\ Sendai 980 and *Department of Pharmacological Research, \\ Teikoku Hormone Mfg. Co., Ltd., Shimosakunobe, Kawasaki 213
}

\begin{abstract}
OJima, M. and Kambegawa, A. Plasma Concentrations of 18-Hydroxy-11Deoxycorticosterone and 18-Hydroxycorticosterone Simultaneously Measured in Normal Subjects and Adrenocortical Disorders. Tohoku J. exp. Med., 1980, 132 (1), 75-85 - A method for the simultaneous measurement of 18-hydroxy-11-deoxycorticosterone (18-OH-DOC) and 18-hydroxycorticosterone (18-OH-B) in human peripheral plasma has been developed. The present method consists of extracting plasma with dichloromethane, separating the 18-OH-DOC and 18-OH-B from other steroids on a Sephadex LH-20 column and quantitating each steroid by radioimmunoassay. The mean plasma level of 18-OH-DOC at 8:00 a.m. was $8.2 \pm 3.9 \mathrm{ng} / 100 \mathrm{ml}$ (mean士s.D.) in normal males. It was $7.8 \pm 2.6 \mathrm{ng} / 100 \mathrm{ml}$ in the follicular phase of normal females and $11.5 \pm 2.8 \mathrm{ng} / 100 \mathrm{ml}$ in the luteal phase. The corresponding level of $18-\mathrm{OH}-\mathrm{B}$ in normal males was $10.3 \pm 4.2 \mathrm{ng} /$ $100 \mathrm{ml}$ and in the follicular and luteal phases of normal females was $12.4 \pm 4.5 \mathrm{ng} /$ $100 \mathrm{ml}$ and $13.8 \pm 4.1 \mathrm{ng} / 100 \mathrm{ml}$, respectively. No sex differences nor difference between the phases of the menstrual cycle was confirmed. Plasma levels of the two steroids were not rarely high in patients with Cushing syndrome due to adrenocortical hyperplasia and carcinoma, primary aldosteronism, idiopathic hyperaldosteronism and congenital $17 \alpha$-hydroxylase deficiency, while they were usually within the normal range in cases of Cushing syndrome due to adrenocortical adenoma. These steroid levels were significantly low in patients with Addison's disease. 18-hydroxy-11-deoxycorticosterone; 18-hydroxycorticosterone; adrenocortical disorders; Cushing syndrome; primary aldosteronism
\end{abstract}

18-Hydroxy-11-deoxycorticosterone (18-OH-DOC) and 18-hydroxycorticosterone (18-OH-B) were shown to be produced by the adrenals both in man and animals (Ulick and Vetter 1965; de Nicola and Birmingham 1968; Birmingham et al. 1968). In man, the plasma levels of $18-\mathrm{OH}-\mathrm{DOC}$ and $18-\mathrm{OH}-\mathrm{B}$ were demonstrated in normal subjects (Mason et al. 1975; Martin et al. 1975; Chandler et al. 1976; Williams et al. 1976), but scarcely in patients with adrenal diseases. The present paper concerns a new method for the simultaneous measurement of 18-OH-DOC and $18-\mathrm{OH}-\mathrm{B}$ in the single extract of plasma by radioimmunoassay and its application to the patients with adrenocortical disorders.

Received for publication, July 24, 1979. 


\section{Materials and Methods}

Chemicals, solvents and steroids

All organic solvents including ethanol, methanol, dichrolomethane and toluene were of analytical reagent grade (Wako Pure Chemicals) and were not further purified. The 18-OH-DOC standard was provided by Steraroids and the 18-OH-B standard by Fulka Seientific. These two steroids were diluted to the concentrations of $10 \mu \mathrm{g} / \mathrm{ml}$ and $100 \mathrm{ng} / \mathrm{ml}$ with ethanol containing $0.1 \%$ pyridine and stored at $-20^{\circ} \mathrm{C} . \quad\left[1,2-{ }^{3} \mathrm{H}\right]-18-0 H-D O C$ (SA 51 $\mathrm{Ci} /$ mmole, The Radiochemical Center) and $\left[1,2-{ }^{3} \mathrm{H}\right]-18-\mathrm{OH}-\mathrm{B}$ (SA $42 \mathrm{Ci} / \mathrm{mmole}$, The Radiochemical Center) were purified by thin layer chromatography in the solvent system of toluene-methanol $(80: 20)$ and stored in $0.1 \%$ pyridine ethanol at $-20^{\circ} \mathrm{C}$. All the water used through this procedure was bidistilled. Chromatographic columns consisted of borosilicate glass tubes, $65 \mathrm{~cm}$ long, with an internal diameter of $10 \mathrm{~cm}$ fitted with a glass stop cock.

\section{Antibodies}

18-OH-DOC-3-(O-carboxymethyl)-oxime (18-OH-DOC-3-CMO) and 18-OH-B-3 (0-carboxymethyl)-oxime (18-OH-B-CMO) were prepared using a method modified from Erlanger et al. (1957). The coupling to bovine serum albumin (BSA) was done according to the method of Erlanger et al. (1957). Antiserum to 18-OH-DOC was produced by injections of 18OH-DOC-3-OCM-BSA in $0.5 \mathrm{ml}$ of normal saline solution emulsified with $0.5 \mathrm{ml}$ Freund's adjuvant to rabbits. Antiserum to 18-OH-B-3-OCM-BSA was produced by injections in the same way.

\section{Outline of the assay}

Outline of the assay is shown in Fig. 1. The method used was a modification of Nowaczynski et al. for aldosterone (1974). An aliquot of 1.0-2.0 ml of plasma was added to a tube containing $20,000 \mathrm{dpm}$ of $18-\mathrm{OH}-\mathrm{DOC}$ and $18-\mathrm{OH}-\mathrm{B}$. The plasma was extracted with 15 vol of dichloromethane and the extract was washed consecutively with $1 / 10$ vol of $1 \mathrm{~N} \mathrm{NaOH}, 0.01 \mathrm{~N} \mathrm{NaOH}$ and water. The extract was evapolated under $50^{\circ} \mathrm{C}$. Sephadex LH-20 gel previously swollen overnight in water was powered down the column to a height of $55 \mathrm{~cm}$. The dried residue of the extract was redissolved in $0.2 \mathrm{ml}$ of a mixture of methanol and water $(1: 1, \mathrm{vol})$, and this solution was applied to this column,

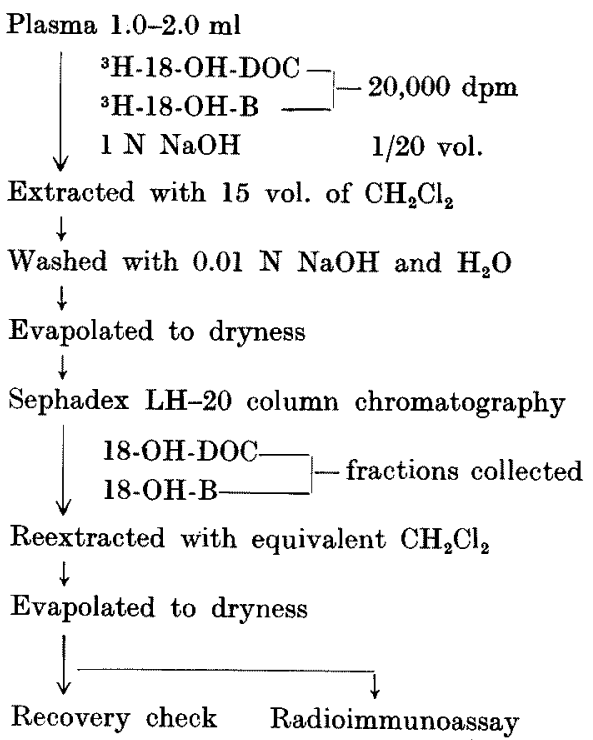

Fig. 1. Outline of the method. 
eluted with water, and $3 \mathrm{ml}$ fractions were collected. After collecting the appropriate elute fractions for 18-OH-DOC and 18-OH-B from the column, an aliquot was counted for estimating recovery and the other was analyzed for steroid content by radioimmunoassay. The samples and standards containing $0,10,20,50,100,200,300,400$ and $500 \mathrm{pg}$ of unlabeled steroids to which $10,000 \mathrm{dpm}$ of tritiated steroids (equivalent to the dose of the average sample aliquots) were dried down.

Antiserum solution was prepared by diluting the antiserum to appropriate concentration with borate buffer $(0.05 \mathrm{M}, \mathrm{pH} 7.8)$ containing $0.05 \mathrm{wt} / \mathrm{vol} \%$ BSA (Fraction V) and $0.05 \mathrm{wt} / \mathrm{vol} \%$ pepsin-treated human immunoglobulin as a carrier protein. The dried samples and standards were dissolved in $0.25 \mathrm{ml}$ of the dilute antiserum. These tubes were incubated in a cold room at $4^{\circ} \mathrm{C}$ overnight. To separate free steroids from the antibody bound, $0.25 \mathrm{ml}$ of saturated ammonium sulfate was added to each tube, incubated for $10 \mathrm{~min}$ at room temperature, and centrifuged at $2,500 \mathrm{rpm}$. One fifth $\mathrm{ml}$ of the resulting supernatant was transferred to a scintillation vial for counting.

Subjects

In total 57 cases (30 healthy controls, 24 patients with hyperadrenocorticalism and 3 with hypoadrenocorticalism) were subjected to the study. For healthy controls 20 males and 10 females aged 19-36 years without evidence of any metabolic or endocrine disorder were adopted. For hyperadrenocorticalism 12 patients with Cushing syndrome (7 due to adrenocortical hyperplasia, 4 due to adrenocortical adenoma, and 1 due to adrenocortical carcinoma,) 8 with primary aldosteronism, 2 with idiopathic hyperaldosteronism and 2 with congenital $17 \alpha$-hydroxylase deficiency were served. For hypoadrenocorticalism 3 patients with Addison's disease were adopted.

Blood sampling was performed at 8:00 a.m. after lying for $2 \mathrm{hr}$ on an ad lib sodium intake. The samples in females were drawn within 6 days from the onset of menstruation. In addition, plasma sampling was done after the 15th day of the normal menstrual cycle.

\section{RESULTS}

\section{Evaluation of the method}

Recovery. The recovery of tritiated $18-0 \mathrm{H}-\mathrm{DOC}$ added to the plasma samples ranged from 67 to $88 \%$ with the mean of $74 \pm 7 \%$ at the end of the extraction and purification procedure in the analysis of 30 plasma samples. The recovery in 18$\mathrm{OH}-\mathrm{B}$ assay ranged from 65 to $82 \%$ and the mean value was $71 \pm 8 \%$.

Blank values. In the $18-\mathrm{OH}-\mathrm{DOC}$ assay, the mean level of water blank was $6.7 \pm 1.5 \mathrm{pg}$ (mean \pm s.D.) for 20 experiments. In the $18-0 \mathrm{H}-\mathrm{B}$ assay, the mean value for water blank was $5.1 \pm 1.8 \mathrm{pg}$ in 20 experiments. Since the average blank was outside of the limit of sensitivity of the assay system, no correction for it was made.

Column separation. Elution diagram of a mixture of steroids on this Sephadex LH-20 column in water is given in Fig. 2. The separation of 18-OH-DOC and 18$\mathrm{OH}-\mathrm{B}$ from other steroids, especially aldosterone, cortisol (F) and corticosterone (B), was satisfactory.

Specificity. Specificity of this assay for 18-OH-DOC and 18-OH-B lied in the combination of the high resolution Sephadex LH-20 column chromatography and adoption of relatively specific antisera.

To determine the titer of the antisera, serial dilutions $(1: 1,000-1: 50,000)$ were incubated for overnight at $4^{\circ} \mathrm{C}$. The most satisfactory dilutions were $1: 15,000$ for 18-OH-DOC and 1:10,000 for 18-OH-B (Fig. 3). Specificity of the 18-OH-DOC- 
3-CMO antibody (Ojima 1978) and the 18-OH-B-3-CMO antibody were shown in Table 2. The $18-\mathrm{OH}-\mathrm{DOC}$ antiserum had a cross reaction in $29.4 \%$ to aldosterone, $12.0 \%$ to $18-\mathrm{OH}-\mathrm{B}, 0.2 \%$ to $\mathrm{B}$, and under $3.7 \%$ to the other steroids. The 18 $\mathrm{OH}-\mathrm{B}$ antiserum showed $24.5 \%$ cross reactivity to $18-\mathrm{OH}-\mathrm{DOC}$, and $11.7 \%$ to aldosterone, whereas under $1 \%$ to $\mathrm{F}, \mathrm{B}$, and the other steroids. In this assay, the separation of 18-OH-DOC and 18-OH-B from aldosterone, $\mathrm{B}$ and $\mathrm{F}$ was complete, and there was no interference (Table 1).

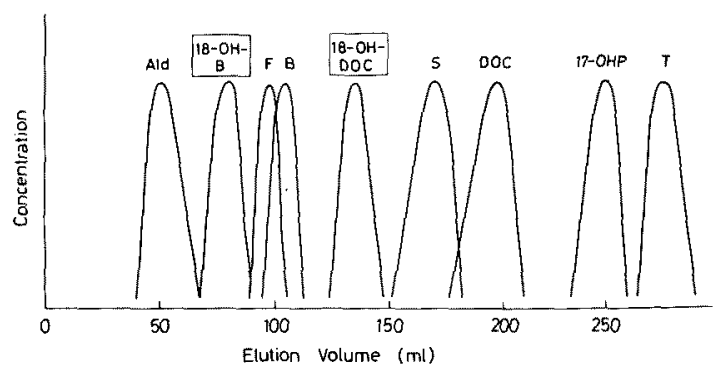

Fig. 2. Elution diagram of a mixture of steroids on Sephadex LH-20 in water. Bed dimensions: $1 \times 55 \mathrm{~cm}$, Ald: aldosterone, S: 11-deoxycortisol, 17-OHP: 17o-hydroxyprogesterone, $\mathrm{T}$ : testosterone.
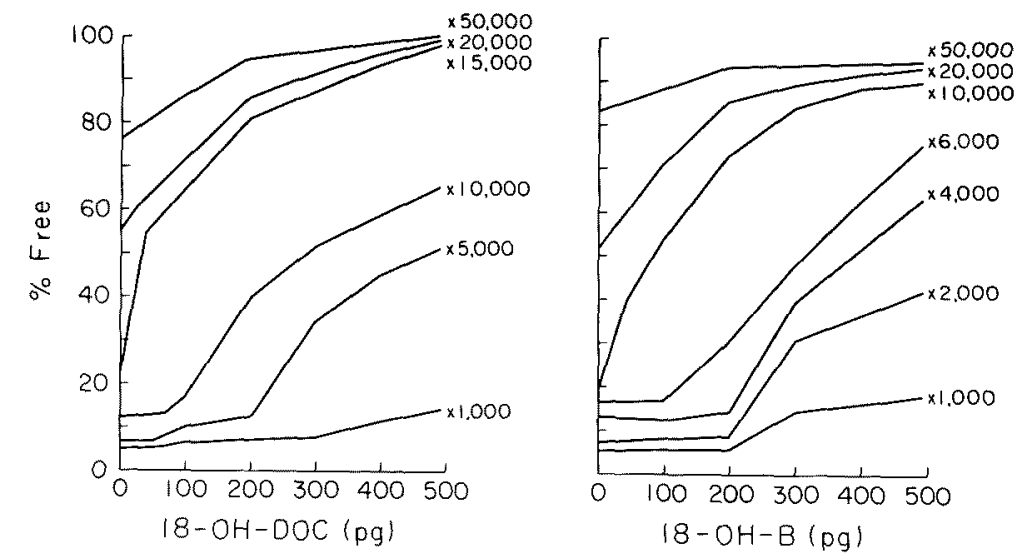

Fig. 3. The titer of the antisera.

Sensitivity. Typical standard dose-response curves for 18-OH-DOC and 18$\mathrm{OH}-\mathrm{B}$ are shown in Fig. 4. The useful ranges of the standard curve were from 10 through $500 \mathrm{pg}$. The limits of detection, defined as the blank measurement plus $2.5 \times$ s.D. were $13.8 \mathrm{pg}$ in the $18-\mathrm{OH}-\mathrm{DOC}$ assay and $13.9 \mathrm{pg}$ in the 18-OH-B assay (Ekins and Newman 1970).

Accuracy and precision. The following amounts of 18-OH-DOC were added to $0.5 \mathrm{ml}$ of water; 10,20,50,100,200 and $400 \mathrm{pg}$. Six or 7 experiments were repeated and a satisfactory recovery was indicated by the regression line between the values of 18-OH-DOC added and recovered (Table 2). The same experiments 
TABLE 1. Accuracy of the method

\begin{tabular}{lcc} 
Steroids & \multicolumn{2}{c}{ Percent cross-reaction } \\
\cline { 2 - 3 } & $\begin{array}{c}\text { 18-OH-DOC-3-CMO } \\
\text { antiserum }\end{array}$ & $\begin{array}{c}\text { 18-OH-B-3-CMO } \\
\text { antiserum }\end{array}$ \\
\hline 18-OH-DOC & 100 & 24.5 \\
18-OH-B & 12.00 & 100 \\
Cortisol & 0.032 & 0.022 \\
Cortisone & 0.032 & 0.084 \\
Corticosterone & 0.022 & 0.022 \\
DOC & 0.22 & 0.484 \\
11-Deoxycortisol & 3.67 & 0.650 \\
Aldosterone & 29.4 & 11.7 \\
Pregnenolone & 0.032 & 0.030 \\
17-OH-pregnenolone & 0.52 & 0.030 \\
Progesterone & 0.049 & 0.055 \\
17-OH-progesterone & 0.032 & 0.030 \\
Dehydroepiandrosterone & 0.058 & 0.055 \\
Androstenedione & 3.20 & 0.168 \\
Estradiol & 0.29 & 0.168 \\
Testosterone & 1.87 & 0.650 \\
\hline
\end{tabular}

TABLE 2. The specificity of 18-OH-DOC-3-CMO antiserum and 18-OH-B-3-CMO antiserum

\begin{tabular}{rrrr}
\hline Steroid added (pg) & $\begin{array}{c}\text { Steroid quantified (pg) } \\
\text { Mean } \pm \text { s.D. }\end{array}$ & Regression equation \\
\hline 18-OH-DOC & 0 & $7.9 \pm 3.6$ & \\
& 20 & $28.3 \pm 3.1$ & \\
& 50 & $57.4 \pm 6.2$ & \\
& 100 & $109.7 \pm 1.4$ & \\
& 200 & $218 \pm 8.5$ & \\
& 400 & $414 \pm 28.2$ & \\
\hline 18-OH-B & 0 & $8.1 \pm 2.4$ & \\
& 20 & $26.0 \pm 5.5$ & \\
& 50 & $54.5 \pm 7.1$ & $Y=1.02 X \pm 6.3$ \\
& 100 & $106.8 \pm 11.2$ & \\
& 200 & $212 \pm 12.6$ & \\
& 400 & $417 \pm 20.8$ & \\
\hline
\end{tabular}

were also performed on 18-0H-B. A correlation of steroids added and recovered was also satisfactory (Table 2).

Precision within assays was examined by measuring the 18-OH-DOC and $18-$ OH-B concentrations in the plasma of normal subjects. The coefficient of variation in the assay of 18-OH-DOC evaluated by analyzing 10 samples in the same duplicate assay was $13.4 \%$, and that for 18-OH-B estimated by analysis in the same way was $15.5 \%$. Precision between assays was determined with 4 different assays on 5 samples of normal subjects. The coefficient of variations between assays for $18-\mathrm{OH}-\mathrm{DOC}$ and $18-\mathrm{OH}-\mathrm{B}$ were $14.6 \%$ and $12.1 \%$, respectively. 

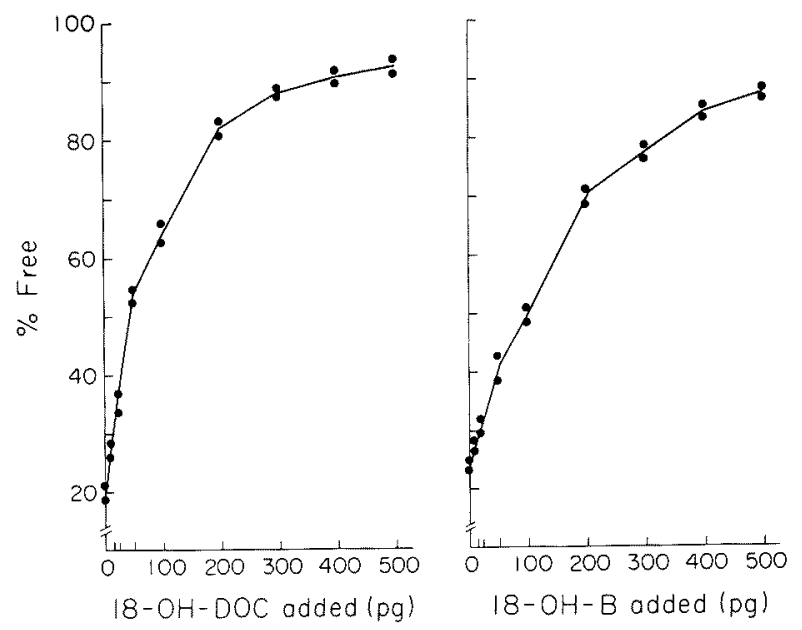

Fig. 4. Typical dose-response curves for 18-OH-DOC and 18-OH-B.

\section{Plasma values}

The vsults are summarized in Figs. 5 and 6 .

Controls. In 20 healthy males, the plasma 18-OH-DOC levels were $3.2-18.7$ $\mathrm{ng} / 100 \mathrm{ml}$ (mean \pm s.D., $8.2 \pm 3.9 \mathrm{ng} / 100 \mathrm{ml}$ ) on a random diet. The correpsonding levels of plasma $18-0 H-B$ were $2.7-19.8 \mathrm{ng} / 100 \mathrm{ml}(10.3 \pm 4.2 \mathrm{ng} / 100$ $\mathrm{ml}$ ). In 10 healthy females, the plasma 18-0H-DOC levels within 6 days from the onset of menstruation were $3.6-14.8 \mathrm{ng} / 100 \mathrm{ml}(7.8 \pm 2.6 \mathrm{ng} / 100 \mathrm{ml})$. The corresponding levels of $18-\mathrm{OH}-\mathrm{B}$ were $4.1-17.8 \mathrm{ng} / 100 \mathrm{ml}(12.4 \pm 4.5 \mathrm{ng} / 100 \mathrm{ml})$. The mean level of plasma $18-0 \mathrm{H}-\mathrm{DOC}$ after the 15 th day of the menstrual cycle was

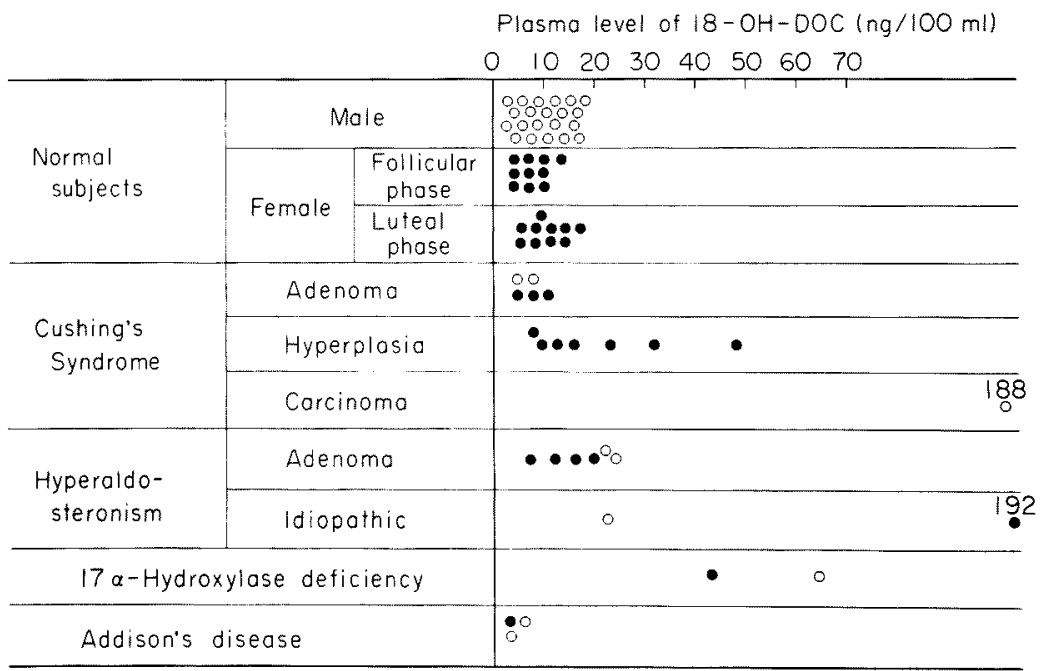

Fig. 5. Plasma levels of 18-OH-DOC in normal subjects and patients with various adrenocortical disorders. 
$11.5 \pm 2.8 \mathrm{ng} / 100 \mathrm{ml}$ (range: $4.5-17.5 \mathrm{ng} / 100 \mathrm{ml}$ ), and the corresponding level of 18-OH-B was $13.8 \pm 4.1 \mathrm{ng} / 100 \mathrm{ml}$ (range: $4.9-19.8 \mathrm{ng} / 100 \mathrm{ml}$ ).

Hyperadrenocorticalism. The plasma concentrations of 18-OH-DOC and 18-OH-B in 4 patients with Cushing syndrome due to adrenocortical adenoma were within normal range. The plasma levels of 18-OH-DOC and 18-OH-B were elevated in 3 out of 7 patients with Cushing syndrome due to bilateral adrenocortical hyperplasia. The remaining one patient with Cushing syndrome due to adrenocortical carcinoma showed significantly high levels of 18-OH-DOC and 18-OH-B ( $p$ $<0.001)$.

In 8 patients with primary aldosteronism, the plasma levels of 18-OH-DOC and 18-OH-B were elevated in 3 out of 6 and 5 out of 8 , respectively.

In 2 patients with idiopathic hyperaldosteronism studied, the plasma levels of both 18-OH-DOC and 18-OH-B were significantly increased $(p<0.001)$.

Hypoadrenocorticalism. Plasma levels of 18-OH-DOC and 18-OH-B in 4 patients with Addison's disease were decreased.

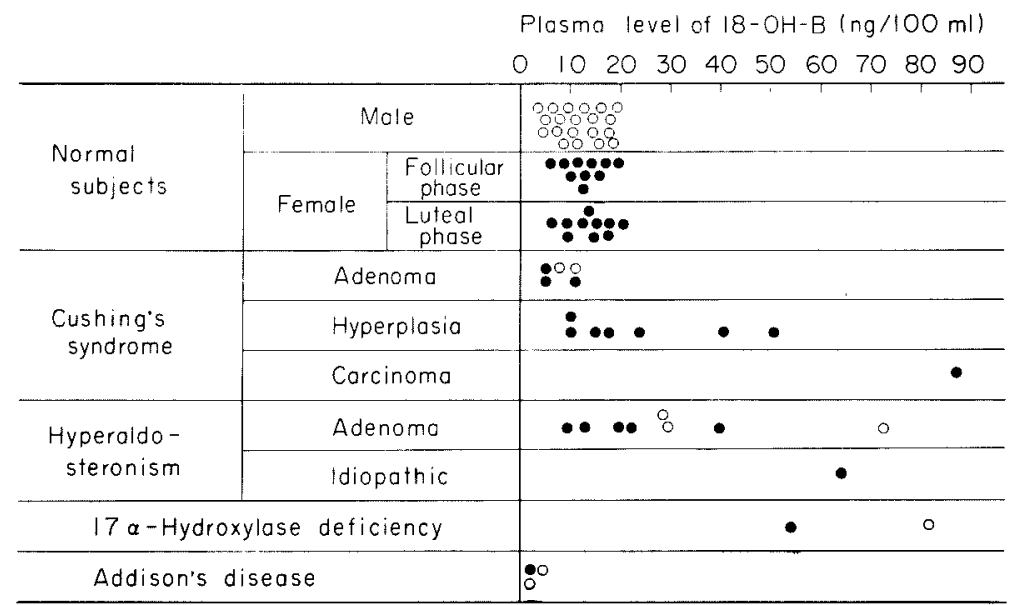

Fig. 6. Plasma levels of 18-O-H-B in normal subjects and patients with various adrenocortical disorders.

\section{Discussion}

Methods for the simultaneous measurement of plasma levels of 18-OH-DOC and 18-OH-B by radioimmunoassay have developed. Certain authors (Martin et al. 1975, Chandler et al. 1976; Williams et al. 1976; Ojima et al. 1978) measured individual plasma levels of 18-OH-DOC and 18-OH-B, but few evaluated these two steroids simultaneously in the single extract. The major problems for establishing this procedure may be the following three: effective separation of the steroids, adequate purification, and sufficiently sensitive quantitation.

The antibodies to $18-\mathrm{OH}-\mathrm{DOC}$ and $18-\mathrm{OH}-\mathrm{B}$ used in this assay were relatively high in specificity, having cross reaction less than $1 \%$ to cortisol and $B$ which 
are present in much higher concentrations than $18-0 \mathrm{H}-\mathrm{DOC}$ and $18-\mathrm{OH}-\mathrm{B}$ in the normal human subjects. Although these antisera had a slight cross reactivity to aldosterone which has the chemical structure closely resembled those of $18-\mathrm{OH}-\mathrm{DOC}$ and 18-OH-B, the chromatographic purification of extract was highly resolutive and induced no trouble through the assay. Dominguez (1965) and Damasco and Lantos (1975) suggested that $18-\mathrm{OH}-\mathrm{DOC}$ and $18-\mathrm{OH}-\mathrm{B}$ exhibit a certain instability in several organic solvents, e.g. methanol, acetone, ethanol and benzene, where they form an unidenified but less polar compound. However, the conversion was minimized in the present assay using ethanol containing $0.1 \%$ pyridine for dilution of 18-OH-DOC and 18-OH-B according to the report of Chandler et al. (1976). The method developed by the present authors is simple, sensitive and precise enough to solve the above problems and to be applied to the clinical studies.

The mean level of plasma 18-OH-DOC in normal subjects was conformed to be as described previously (Chandler et al. 1976; Williams et al. 1976). The value for $18-0 H-B$ in normal subjects was similar to that obtained by Martin et al. (1975) using 18-0H-B gamma-lactone antibody. There were no differences in the mean levels of 18-OH-DOC or 18-OH-B between follicular and luteal phases in females. There were also no sex differences in the mean levels of plasma 18-OH-DOC or 18$\mathrm{OH}-\mathrm{B}$. This fact disagrees with the case of aldosterone, the major mineralocorticoid, which increases markedly in the mid or late luteal phase of the cycle (Nowaczynski et al. 1974).

So far as we analyzed, the plasma levels of $18-\mathrm{OH}-\mathrm{DOC}$ and $18-\mathrm{OH}-\mathrm{B}$ were increased in patients with Cushing syndrome due to adrenocortical hyperplasia and carcinoma, primary aldosteronism, idiopathic hyperaldosteronism and $17 \alpha$ hydroxylase deficiency. Approximately $40 \%$ of the patients with Cushing syndrome due to adrenocortical hyperplasia showed elevated levels of plasma 18$\mathrm{OH}-\mathrm{DOC}$ and 18-OH-B. Mild or severe hypertension with or without hypokalemia was common among these patients, whereas the plasma levels of these two steroids remained within normal ranges in all 4 patients with Cushing syndrome due to adrenal adenoma. Melby et al. (1972) provided indirect evidence that 18-OH-DOC is produced mainly by the zona fasciculata under the control of ACTH. The response of plasma 18-OH-DOC to ACTH stimulation and dexamethasone suppression is remarkable (Chandler et al. 1976; Tuck et al. 1977). Therefore, patients with chronic mild excess of ACTH, e.g. Cushing syndrome due to adrenal hyperplasia may show high levels of plasma 18-OH-DOC. On the other hand, patients with Cushing syndrome due to adrenal adenoma may have no increase in secretion of 18-OH-DOC due to suppression of ACTH secretion because of the autonomous cortisol production by the tumor. Martin et al. (1975) pointed out that the secretion of $18-\mathrm{OH}-\mathrm{B}$ rised in response to sodium deprivation. For this reason, sodium deprivation might potentiate the response of aldosterone to angiotensin II by increasing the synthesis of the precursor 18-OH-B. Our data of the 18-OH-B behavior in Cushing syndrome suggested that hypersecretion of ACTH could also stimulate the $18-\mathrm{OH}-\mathrm{B}$ release in man. In one patient with Cushing 
syndrome due to adrenocortical carcinoma the plasma levels of 18-OH-DOC and 18-OH-B were markedly elevated. This patient had high levels of the other 12 steroids so far as analyzed (Fig. 7). The mechanism of hypersecretion of all these steroids was not clear, but this steroidogenic pattern may be characteristic in some patients with adrenocortical carcinoma.

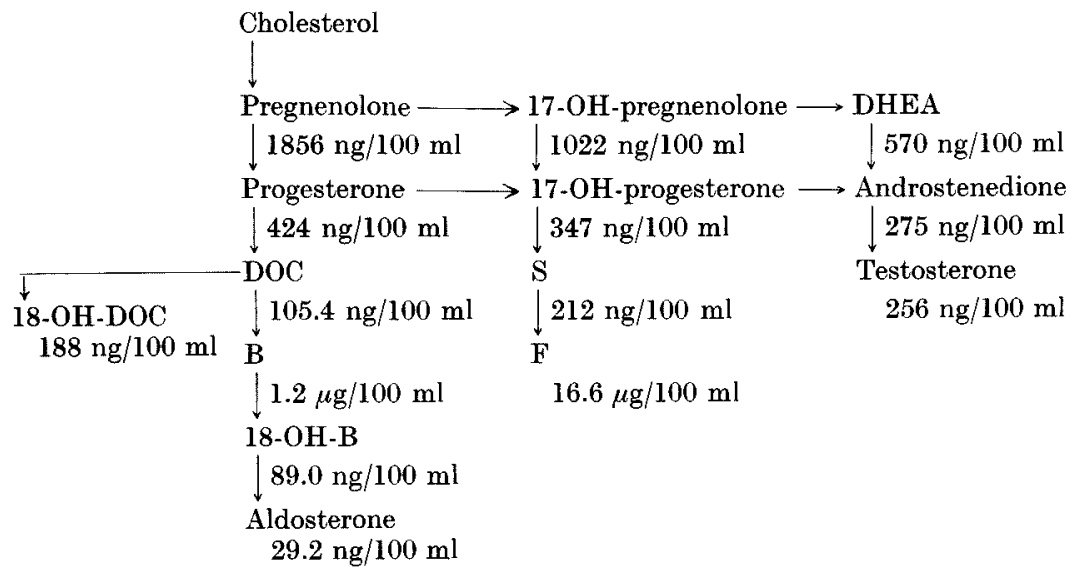

Fig. 7. Plasma levels of various steroids in a patient with Cushing syndrome due to adrenocortical carcinoma.

About $40 \%$ patients with primary aldosteronism exhibited the elevated concentrations of plasma $18-\mathrm{OH}-\mathrm{DOC}$ and 18-OH-B. Two patients with idiopathic hyperaldosteronism showed clearly elevated levels of the plasma 18-OH-DOC and 18-OH-B. These data corresponded well to those of urinary 18-OH-DOC excretion (Melby et al. 1972). The reasons for the hypersecretion of 18-OH-DOC and 18$\mathrm{OH}-\mathrm{B}$ are not clear, but it appears likely that these two steroids are mainly produced by aldosteronoma tissue and secreted into the blood. Small but significant conversion of 18-OH-DOC to aldosterone in the normal adrenal cortex was demonstrated by in vitro incubation. Conversion of $18-0 H-D O C$ to aldosterone by the tumor tissue was very active in aldosteronoma, and there was much more conversion to 18-OH-B than to aldosterone (Grekin et al. 1973). Melby et al. (1972) reported that the plasma concentration of $18-\mathrm{OH}-\mathrm{DOC}$ was elevated in the venous blood drained from the adrenal with aldosteronoma and the urinary 18-OH-tetrahydro-DOC excretion was elevated in a few patients with primary aldosteronism. These facts suggest that tumors of primary aldosteronism are capable of hypersecreting 18-OH-DOC and 18-OH-B.

In 2 patients with hypertension and hypokalemia due to $17 \alpha$-hydroxylase deficiency had intensively high levels of plasma $18-\mathrm{OH}-\mathrm{DOC}$ and 18-OH-B. It is possible that $17 \alpha$-hydroxylation of pregnenolone is diminished and the synthesis of progesterone, $\mathrm{DOC}$ and $\mathrm{B}$ are increased, which may result in the hypersecretion of $18-\mathrm{OH}-\mathrm{DOC}$ and $18-\mathrm{OH}-\mathrm{B}$.

18-OH-DOC and 18-OH-B have approximately the same level in the peripheral 
plasma as aldosterone in the normal subjects. They are said to be less potent and less significant in electrolyte homeostasis than aldosterone. However, in some clinical conditions like Cushing syndrome and $17 \alpha$-hydroxylase deficiency, excess of 18-OH-DOC and 18-OH-B might induce hypertension and/or hypokalemia at some extent.

\section{Acknowledgment}

We gratefully acknowledge Prof. Nobuaki Sasano, Department of Pathology, Tohoku University School of Medicine, for his constant interest and guidance in this investigation. We thank Mrs. Shinko Kobayashi and Miss Mutsumi Yamaguchi for assistance in preparation of this manuscript.

This study was supported in part by a Research Grant from the Intractable Diseases Division, Public Health Bureau, Ministry of Health and Welfare, Japan.

\section{References}

1) Birmingham, M.K., McDonald, M.L. \& Rochefort, J.G. (1968) Adrenal function in normal rats and in rats bearing regenerated adrenal glands. In: Functions of the Adrenal Cortex, vol. II, edited by K.W. McKerns, Appleton-Century-Croft, New York, pp. $647-690$.

2) Chandler, D.W., Tuck, M. \& Myes, D.M. (1976) The measurement of 18-hydroxy-11deoxycorticosterone in human plasma by radioimmunoassay. Steroids, 27, 235-246.

3) Damasco, M.C. \& Lantos, C.P. (1975) The existence of two interconvertible forms of 18-hydroxycorticosterone: Is one of them an active precursor of aldosterone? $J$. Steroid. Biochem., 6, 69-74.

4) de Nicola, A.F. \& Birmingham, M.K. (1968) Biosynthesis of 18-hydroxydeoxycorticosterone from deoxycorticosterone $-{ }^{14} \mathrm{C}$ by the human adrenal gland. $J$. clin. Endocr., 28, 1380-1383.

5) Dominguez, O.U. (1965) The presence of two interconvertible forms of 18-hydroxy-11deoxycorticosterone. Steroids, 6, Suppl. 2, 29-49.

6) Ekins, R. \& Newman, B. (1970) Theoretical aspects of saturation analysis. Acta endocr. Suppl. 147, 11-36.

7) Erlanger, B.F., Broek, F., Beiser, S.M. \& Lieberman, S. (1957) Steroid protein conjugates I. Preparation and characterization of conjugates of bovine serum albumin with testosterone and with cortisone. J. biol. Chem., 228, 713-727.

8) Grekin, R.J., Dale, S.L. \& Melby, J.C. (1973) The role of the 18-hydroxy-11-deoxycorticosterone as a precursor in human adrenal tissue in vitro. J. clin. Endocr., 37, 261-264.

9) Martin, V.I., Edwards, C.R.W., Biglieri, E.G., Vinson, G.P. \& Bartter, F.C. (1975) The development and application of a radioimmunoassay for 18-hydroxycorticosterone. Steroids, 26, 591-604.

10) Mason, P.A., Fraser, R., Morton, J.J., Semple, P.F. \& Wilson, A. (1975) Effect of sodium deprivation and angiotensin II infusion on the peripheral plasma concentrations of 18-hydroxycorticosterone, aldosterone and other corticosteroids in man. $J$. Endocr., 64, 277-288. (Abstract)

11) Melby, J.C., Dale, S.L., Grekin, R.J., Gaunt, R. \& Wilson, T.E. (1972) 18-hydroxy-11deoxycorticosterone secretion in experimental and human hyertension. Recent Progr. Hormon. Res., 28, 287-339.

12) Nowaczynski, W., Sasaki, C. \& Genest, J. (1974) Radioimmunoassay for aldosterone and normal values under various physiological conditions. J. Steroid Biochem., 5, $123-131$.

13) Ojima, M., Aida, M. \& Kambegawa, A. (1978) Simultaneous determination of plasma 11-deoxycorticosterone, aldosterone and 18-hydroxy-11-deoxycorticosterone in man. Tohoku J. exp. Med., 124, 367-379. 
14) Tuck, M.L., Chandler, D.W. \& Mayes, D.M. (1977) The influences of ACTH dietary sodium, upright posture and angiotensin II on plasma 18-hydroxy-11-deoxycorticosterone levels in normal subjects. J. clin. Endocr., 45, 893-902.

15) Ulick, S. \& Vetter, K.K. (1965) Simultaneous measurement of secretory rates of aldosterone and 18-hydroxycorticosterone. J. clin. Endocr., 25, 1015-1026.

16) Williams, G.H., Barley, L.M. \& Underwood, R.H. (1976) The regulation of plasma 18hydroxy-11-deoxycorticosterone concentration in man. J. clin. Invest., 58, 221-229. 